\title{
POTENTIATION OF ANTHELMINTIC EFFICACY BY THE COMBINATION OF ALKYLRESORCINOLS ${ }^{1}$
}

\author{
HIDEMASA YAMASAKI, CHUZABRO MANNAMİ AND TATEO TAKAOKA
}

Departme it of Parmacology, Okaycma University Medical School, Okayama

Received for publication May 29, 1954

Lamson et al. (1-8) carried out extensive studies on the anthelmintic activity of a large number of alkylhydroxybenzenes and found that substances which apparently act through the cuticle of ascaris were ineffective when their melting points were too high. Harwood ( $(9)$ demonstrated that if such chemicals were kept in the liquid phase by adulteration with certain organic liquids, their $i$ vitro ascaricidal properties were hightened. Considering these reports which suggest a close relationship between the anthelmintic effect and melting points of these substances, the present authors attempted to increase the anthelmintic efficacy by combining certain alkylresorcinols with comparatively slight irritant action.

The present paper gives evidence for the potentiation of in vitro and clinical efficacy by the combination of such chemicals, and describes observations on the toxicity and local irritant properties. Certain physical properties arising from such a combination, were studied in order to elucidate the mechanism of their synergistic effect.

\section{MATERIALS AND METHODS}

Three compounds ${ }^{2}$ were used for most of the experiments, i.e., 4-n-octyl-6-chlororesorcinol (OCR), m.p. $54-54.8^{\circ} \mathrm{C}, 4-n$-octylresorcinol (OR), m.p. $73-74.5^{\circ} \mathrm{C}$, and $4-$ cyclohexyl-6-chlororesorcinol (CHCR), m.p. 89-91 ${ }^{\circ} \mathrm{C}$. These compounds were all less irritant than $4-n$-hexylresorcinol and possessed lower toxicity, OCR being the weakest in these properties $(10,11$ ) (cr. Table 2). Clinical efficacy in the treatment of Ascaris lumbricoides was the lowest for OCR while the other two compounds possessed a medium effect (cf. Figures 1 and 3 ). Approximate solubility at $25^{\circ} \mathrm{C}$ is less than 1:100,000 for OCR, 1:10,000 for OR, and 1:6,000 for CHCR. Surface tension and interfacial tension against liquid paraffin of the saturated solution became lower in the order of OCR, CHCR, and OR. The experiments were carried out on three com-

1) This investigation was supported by a grant from the Ministry of Education for Developmental Scientifi: Research and by a grant from the Prefectural Conference for Countermeasures against Parasitic Disesses in Okayama District.

2) OCR and OR were supplied by the Research Liboratories of Nihon-yushi \& Co., Ltd. Osaka, and CHCR by the Research Laboratories of Shionogi \& Co, Ltd. Amagasaki. 
binations of two each of these compounds. The two compounds were mixed in various ratios, fused, and pulverized.

The in vitro ascaricidal efficacy of these substances and their combinations are shown by the mean value of six experiments by the time required to kill Ascaris lumbricoides of swine in 1:1,000 suspension in 0.9 per cent saline at $37^{\circ} \mathrm{C}$. Detailed description of this method is given elsewhere (12). Other experiments on the in vitro activity were carried out with a nematode, Spinicauda japonica Wilkie, taken from the large intestines of a toad, Bufo vulgaris japonicus Schlegel. In these experiments 30 worms were exposed to a $1: 5,000$ suspension of the drugs in 0.6 per cent saline solution for various periods of time. After cach exposure they were transferred to drug-free saline and the per cent mortality recorded at the end of twenty hours. The temperature of the media was kept at $25^{\circ} \mathrm{C}$.

The clinical anthelmintic efficacy was compared on groups of 10 to 28 persons having similar distribution of the degree of ascaris infestation based on the number of eggs per gram of feces. Based on the egg-counting technique of Stoll (13) before and three weeks after medication, the per cent egg-count reduction and the per cent of patients who became negative (or per cent cured) were calculated for each group. The efficacy of each chemical was judged from these resuits. In some groups, the number of worms expelled during one week after administration of the drug was calculated by actual observation after cach defecation. The dose administered was $1.0 \mathrm{gm}$. for adults and children over 12 years of age and $0.8 \mathrm{gm}$. for children from 8 to 12 years, given in two or three gelatine capsules in one dose on an empty stomach in the morning. Food was withheld for the next four hours.

Surface and interfacial tensions were measured on the filtrates of a 1:1,000 aqueous suspension of each component and combination after standing 24 hours at room temperature. Surface tension was measured at $13.5 \pm 0.5^{\circ} \mathrm{C}$ in dynes $/ \mathrm{cm}$. by the method of du Noüy (14). The interfacial tension of liquid paraffin/filtrate was determined by the same method and also at $25 \pm 0.25^{\circ} \mathrm{C}$ by the drop counting method of Hillyer (15).

Only the in vitro activity was examined with $4-n$-decyl-6-chlororesorcinol ${ }^{3}, \mathrm{~m} . \mathrm{p}$. 59.2-61.2 $2^{\circ} \mathrm{C}, 4-n$-decylresorcinol ${ }^{3}$, m.p. $73.5-75^{\circ} \mathrm{C}$, and their combinations.

\section{RESULTS}

A. OCR and $O R$. 1. Antholmintic properies. The results obtained by the combination of these two compounds are summarized graphically in Figure 1. The experiments were carried out on each component and on mixtures indicated by the percentages of OR on the abscissa. The times of exposure required to kill ascaris in vitro by the majority of the combinations tested are shorter than that of either of the

3) These two compounds were generously synthetized end provided by Pref. S. Uyeo of the Pharmaceutical Institute of Osaka University. 


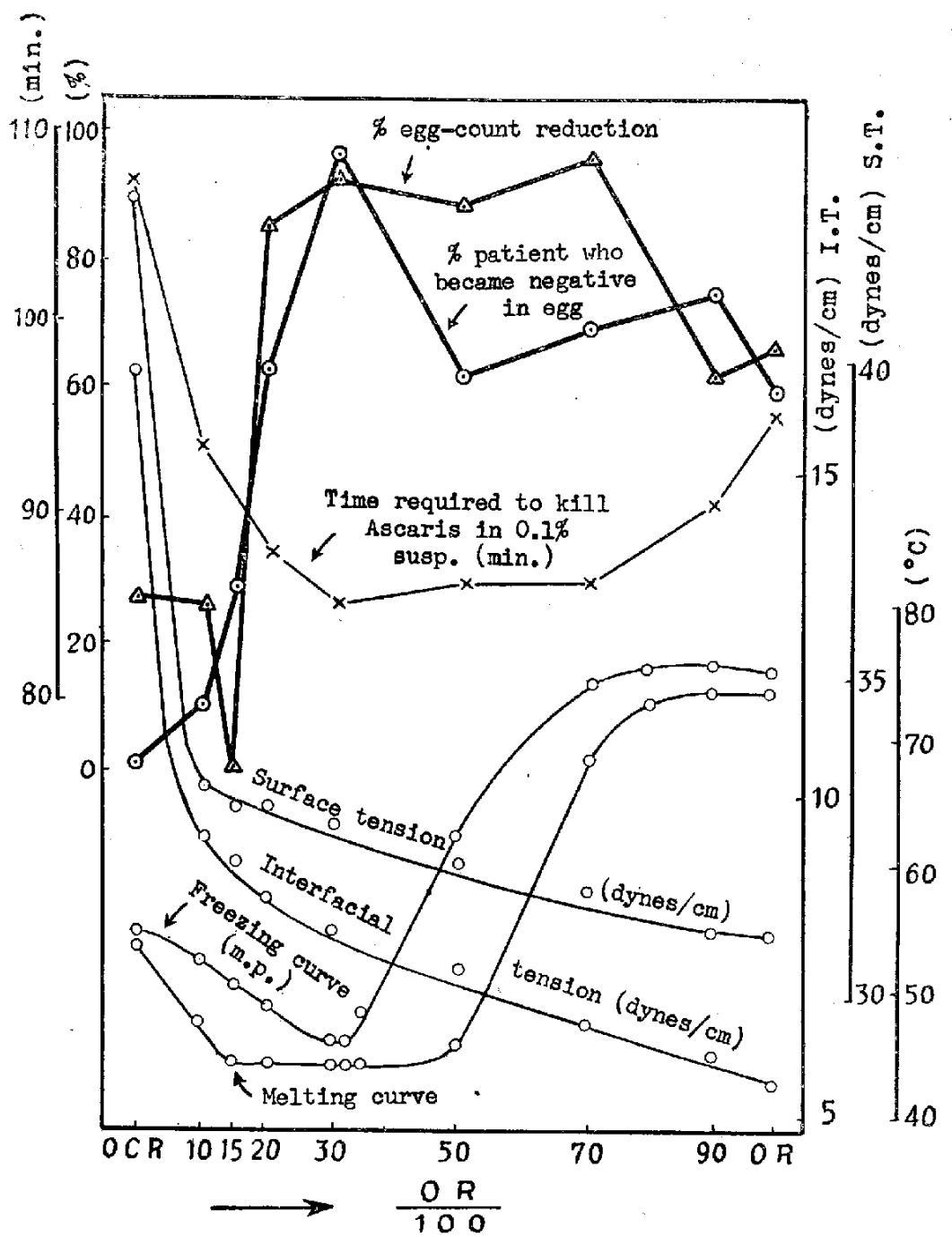

FIG. 1. Combination lof OCR and $O R$. Chart shows.potentiation of the anthelmintic efficacy in man as well as in vitro, with. changes in surface tension and interfacial tension against liquid paraffin of 0.1 per cent suspensions, and in melting points of the mixtures. Curve of the egg-count reduction is based on the percentage as total in exch group. Abscissa denotes percentages of $O R$ content in the mixtures.

components. A 70:30 combination of OCR and OR, which had a comparatively rapid action, was tested against toad nematode by the method described above and, as shown in Figure 2, apparent potentiation also appeared in this case. The two curves in Figure 1, which represent the clinical efficacy also show that the mixtures contain. ing over 20 per cent of $O R$ were more efficient than that of either component alone. It is almost impossible to distinguish the slight differences in 6 fficacy that exist be- 
TABLE 1. Efficacy of the OCR + OR $(70: 30)$ mixture for the treatrent of ascaris infection in man

\begin{tabular}{|c|c|c|c|c|c|c|c|c|c|c|c|c|}
\hline \multirow{2}{*}{$\begin{array}{l}\text { Age } \\
\text { and } \\
\text { sex }\end{array}$} & \multirow{2}{*}{$\begin{array}{l}\text { Eggs per gram } \\
\text { feces before } \\
\text { treatment }\end{array}$} & \multicolumn{8}{|c|}{ Days after treatment and no. worms in feces } & \multirow{2}{*}{$\begin{array}{l}\text { Eggs } \\
\text { feces } \\
\text { after }\end{array}$} & \multirow{2}{*}{$\begin{array}{c}\text { per } \\
3 \\
\text { tre }\end{array}$} & \multirow{2}{*}{$\begin{array}{l}\text { gram } \\
\text { weeks } \\
\text { atment }\end{array}$} \\
\hline & & $I^{*}$ & 2 & 3 & 4 & 5 & 6 & 7 & Total & & & \\
\hline $15 \mathrm{M}$ & 400 & & 2 & 3 & & & 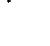 & & 2 & & $\mathbf{0}$ & \\
\hline $44 \mathrm{~F}$ & 550 & & & & 2 & & & & 2 & & 0 & \\
\hline $16 \mathrm{~F}$ & 800 & & & & 2 & & & 2 & 4 & & 0 & \\
\hline $16 \mathrm{~F}$ & 1,300 & & 1 & & 1 & & & & 2 & & 0 & \\
\hline $14 \cdot \mathbf{F}$ & 1,500 & & & 1 & s. & & & & 1 & & 0 & \\
\hline $18 \mathrm{M}$ & 1,700 & & & & 1 & & & & 1 & & 0 & \\
\hline $11 \mathrm{~F}$ & 1,800 & 5 & 1 & 2 & & & & & 8 & & 0 & \\
\hline $19 \mathrm{~F}$ & 2,700 & & 3 & & & & & & 3 & & 0 & \\
\hline $16 \mathrm{~F}$ & 2,800 & & & 2 & & & & & 2 & & $\mathbf{0}$ & \\
\hline 10 & 3,650 & & 1 & & & & & & 1 & & 0 & \\
\hline 26 & 3,800 & 3 & & 1 & 3 & & & & 7 & & 0 & \\
\hline $14 \mathrm{M}$ & 4,300 & & & 1 & & & & & 1 & & 0 & \\
\hline II F & 4,300 & & 6 & & & & & & 6 & & 0 & \\
\hline $52 F$ & 6,300 & & 5 & & & & & & 5 & & 0 & \\
\hline $15 \mathrm{~F}$ & 8,300 & & 5 & & & 1 & & & 6 & & 0 & \\
\hline $1 \mathrm{~F}$ & 8,700 & & 8 & & & & & & 8 & & 0 & \\
\hline $11 \mathrm{~F}$ & 8,750 & & $I$ & & & & & & 1 & & 0 & \\
\hline $8 \mathrm{M}$ & 8,800 & & 2 & & & & & & 2 & & 0 & \\
\hline $10 \mathrm{M}$ & 8,850 & & & 3 & & & & & 3 & & 0 & \\
\hline $14 \mathrm{~F}$ & 14,200 & & 4 & 2 & & & & & 6 & & 0 & \\
\hline $64 \quad \mathrm{~F}$ & 14,800 & & 2 & & & & & & 2 & $\because \quad \because$ & 0 & \\
\hline $15 \mathrm{M}$ & 15,200 & & 5 & & 1 & 2 & 1 & & 9 & & 0 & \\
\hline $14 \mathrm{M}$ & 17,800 & & 31 & & & & & & 31 & $\cdot \therefore$ & 0 & \\
\hline $34 \quad F$ & 28,800 & 35 & & 5 & & & & & 40 & & 0 & \\
\hline $13 \mathrm{M}$ & 34,100 & & & 14 & & 1 & & & 15 & & 0 & \\
\hline $17 \mathrm{M}$ & 35,200 & & & & 8 & & & & 8 & & 0 & $\pi$ \\
\hline $14 \mathbf{F}$ & 37,300 & & & 4 & 3 & & & & 7 & & 0 & \\
\hline $11 \mathrm{M}$ & 100,800 & & 8 & & 45 & 17 & 9 & & 79 & $\cdots$ & 28,90 & \\
\hline $\begin{array}{c}28 \\
\text { patients }\end{array}$ & $\begin{array}{l}\text { Percen } \\
\text { Per ce }\end{array}$ & $g-c o$ & $\mathrm{re}$ & ctio & $\cdots \cdot$ & $\cdots \cdot$ & 6.4 & . & 1), 98 & Gaver & rage) & \\
\hline
\end{tabular}

* The day of medication.

tween these mixtures, but the efficacy of the mixture containing 30 per cent of OR can be said to be extremely potent since it has resulted in complete cure in a group of 28 patients, except for one in which the degree of infection was rather extreme. The result of worm counting in this group is shown in Table 1 , together with the number of eggs in the feces before and after the administration of the drug. This result is much better than that obtained with hexylresorcinol pills (J.P. VI) given to 18 patients under the same conditions. There was a 77.2 per cent reduction in eggcount and a 50 per cent cured rate in the latter. 


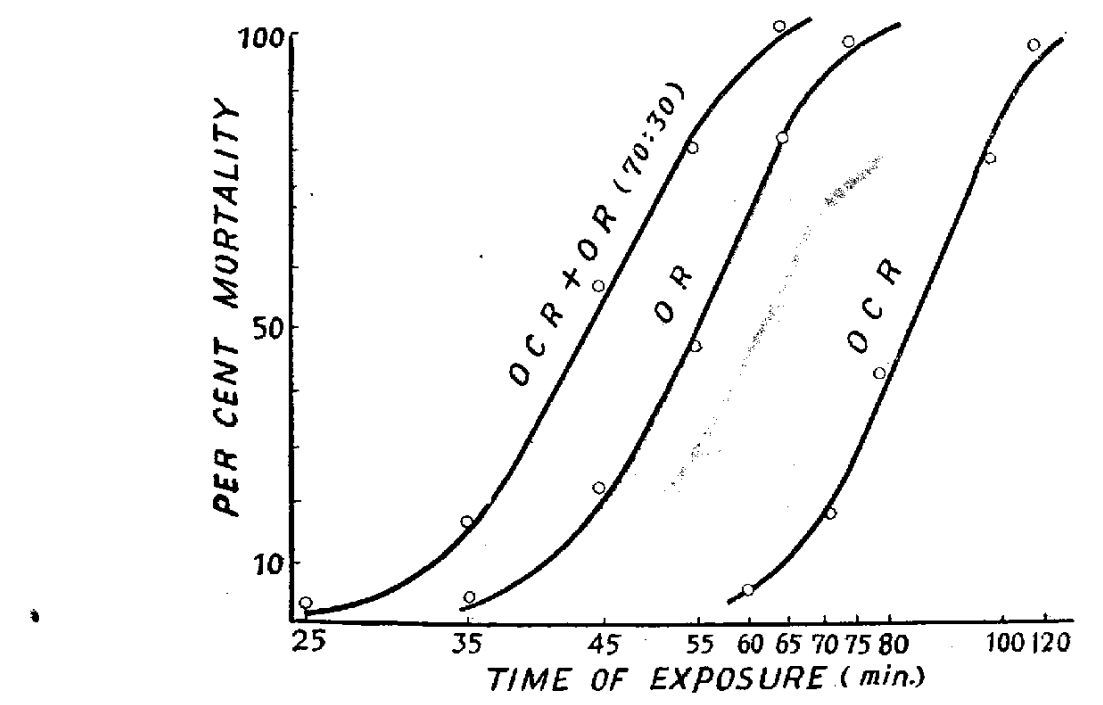

FIG. 2. Mortality curves of $O C R, O R$, and $O C R+O R$ $(70: 30)$ mixture in Spinicauda japonica Wilkie. Percentages of the worms killed after exposures to the drug ( $I: 5,000$ suspensions in 0.6 per cent saline) for the time intervals shown in the abscissa, are plotted as means from each 30 worms.

The melting point of these mixtures was the lowest in that containing 32 per cent of OR. At this ratio the freezing curve and melting curve were the closest, implying the formation of an eutectic mixture. The results shown in Figure 1 suggest the possibility that there is a relationship between the maximum anthelmintic effect and the lowering of the melting point, but there seems to be no relationship between the effectiveness and the lowering of surface and interfacial tensions.

TABLE 2. Comparison of oral toxicity to mice of OCR, $O R, C H C R$, and of some mixtures of these substances, and of hexylresorcinol

\begin{tabular}{|c|c|c|}
\hline Substance & $\begin{array}{c}\mathrm{LD} 50^{*} \\
\text { (mgm./10 gm.) }\end{array}$ & No. of mice \\
\hline OCR & $15.84(13.48-17.91)$ & 48 \\
\hline$O C R+O R(70: 30)$ & $12.86(11.04-14.82)$ & 42 \\
\hline OCR + OR $(70: 30)$ & $11.54(9.96-13.38)$ & $42 \dagger$ \\
\hline $\mathrm{OCR}+\mathrm{OR}(30: 70) \ldots$ & $10.10(7.96-12.39)$ & 48 \\
\hline OR & $9.13(6.84-11.36)$ & 42 \\
\hline OCR + CHCR $(10: 90) \ldots \ldots \ldots$ & $6.15(5.27-7.18)$ & 36 \\
\hline CHCR & $6.26(5.40-7.28)$ & 42 \\
\hline Hexyl resorcinol........ & $5.58(4.77-6.53)$ & $42 \dagger$ \\
\hline
\end{tabular}

*Calculations by van der Waerden's method (16) based on the results 72 hours after the medication and 95 per cent. confidence limits.

†Another stock. 


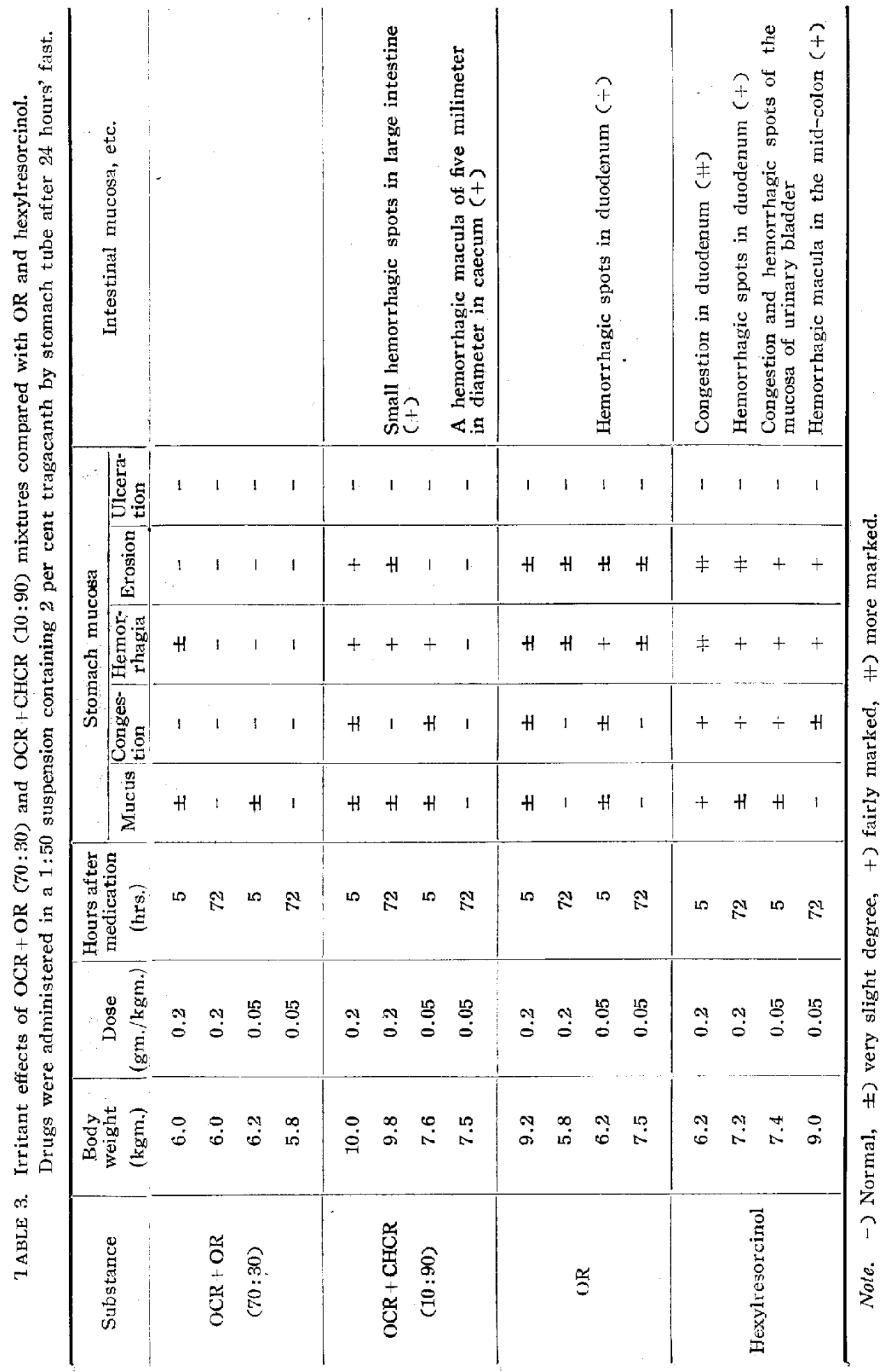


2. Toxicity, local irritant properties, and clinical side-effects. Toxicity of the mixtures in mice by oral administration increased with the increase of OR content, but it never reached beyond the toxicity of OR itself which is the more toxic component of the mixture (Table 2). These mixtures were found to be less irritant than $O R$ alone when applied to the human tongue and the rabbit conjunctiva. It follows, therefore, that such combination failed to cause potentiation of toxicity and local

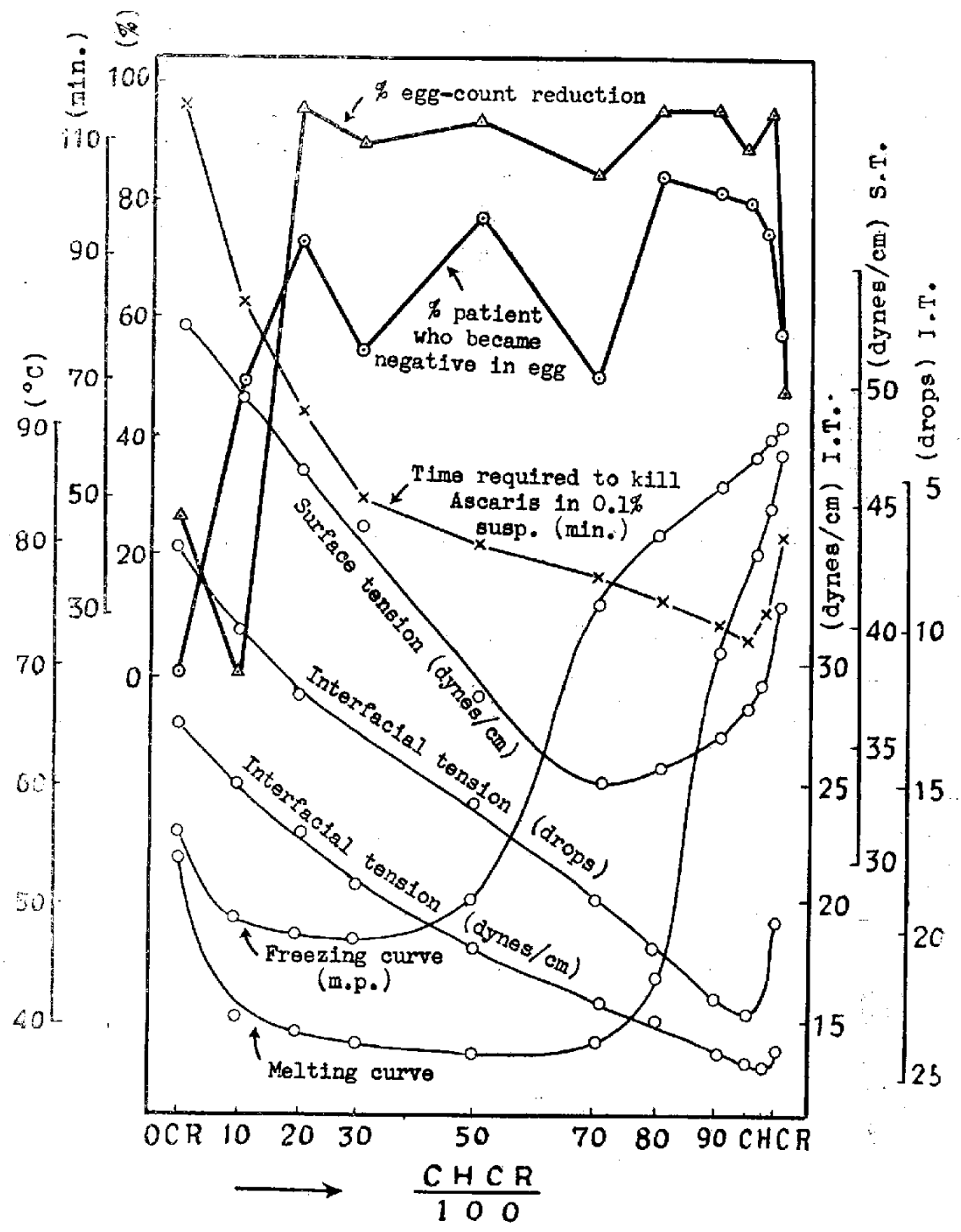

FIC. 2. Combination of OCR and CHCR. Chart shows potentiation of the anchelmintic efficacy in man as well as in vitro, with the changes in surface tension and interfacial tension against liquid paraffin of 0.1 per cent suspensions, and in melting points of the mixtures. Abscissa denotes percentages of $\mathrm{CHCR}$ content in the mixtures. 
irritant properties. What is of practical importance is the fact that these mixtures were not only less toxic than hexylresorcinol (Table 2) but were also far less irritant on the mucous membranes of dog stomach and intestines. The mucosa of these organs in dogs given 0.05 to $0.2 \mathrm{gm} . / \mathrm{kgm}$. dose of a $70: 30$ mixture of OCR and OR showed practically no change, but some traces of irritation were clearly indicated by the administration of $\mathrm{OR}$ and hexylresorcinol, especially in the observations made five hours after the drugs were given (Table 3). No macroscopic changes were observed in other organs of these dogs, and there was no evidence of pathological changes under microscopic examination.

A very few of the patients given these mixtures complained of abdominal pain and nausea, but such symptoms were very slight and of a passing nature, being weaker than those experienced with hexylresorcinol pills. However, rather more cases had diarrhoea which usually was of transitory nature and not severe.

B. OCR and $C H C R$. The anthelmintic potency of the combinations of these two compounds is summarized in Figure 3 , from which it can be seen that definite potentiation is caused both in in vitro ascaricidal activity and in clinical efficacy. The former effect was more pronounced in the mixtures with a larger content of CHCR, but the relationship between the content of CHCR and clinical efficacy was not as marked. The interfacial tension was the lowest in the mixtures containing 90 to 98 per cent of CHCR, which showed the most noticeable ascaricidal properties, but there existed no simple relationship between the lowering of melting point and the efficacy. Toxicity and irritant properties of a mixture containing 90 per cent of CHCR are shown in Tables 2 and 3 , but these values are approximately similar to those of $\mathrm{CHCR}$ alone, so that it may safely be concluded that there was also no potentiation of these properties.

C. $O R$ and $C H C R$. In this case, the mixture containing 90 per cent of $\mathrm{CHCR}$ took a slightly longer time to kill ascarides in $1: 1,000$ suspension, compared to that of CHCR alone, but the maximum potentiation of the clinical effect was observed at this ratio. The interfacial tension and melting points of the mixtures at around this ratio, where the highest clinical efficacy was exhibited, showed steep inclines from the CHCR side to the OR side, but neither agreed with the minimum value. Both the toxicity and irritant properties of these mixtures resembled those of CHCR.

D. 4-n-decyl-6-chlororesorcinol and 4-n-decylresorcinol. The time to death of ascarides in $1: 1,000$ suspensions of these drugs was approximately 26 hours in the former and 160 minutes in the latter, showing their activities to be much weaker than the compounds already considered. There are no quantitative data available regarding the clinical efficacy of these compounds, but there no synergism was found between these two compounds against pig ascaris and toad nematode. 


\section{DISCUSSION}

The first point of interest indicated by the observations described in the present paper is that OCR, OR, and CHCR, which exhibit noticeable potentiation of anthelmintic efficacy by their combination, are chemically similar and the fact suggests that they probably attack the same site in the worm. Such combined effect is an exception to the law of Bürgi (17). The second point of interest is that mixtures of these substances did not increase their toxicity in the mammals tested, including man, or their local irritant properties.

The potentiation of anthelmintic activity by mixing is, at the present stage of investigation, assumed to be due to a change in physical conditions facilitating penetration of these compounds into the worm. One of the bases for such a possibility is the lowering of melting points of the drugs; such observations were made by Harwood (9) and Lamson et al. $(4,5,8)$ who suggested that the lowering of the melting point advantageously affects the contact with and the penetration into ascaris of sparingly soluble anthelmintics. This is borne out by the present series of experiments in which the mixtures possessing potentiated effects had lower melting points than the component present in greater amount. However, it is clear that the anthelmintic properties of these mixtures are not solely controlled by their melting points because there was found no parallelism between the change in potency and the lowering of the melting point. Alexander and Trim (18) reported that the penetration of hexylresorcinol into the body of ascaris was accelerated by surface active agents and this fact was confirmed by a different method by one of the present authors (19). However, no evidence was obtained in the present series of experiments to show that surface or interfacial activity played a decisive rôle in the increase in anthelmintic activity of these mixtures.

With regard to the second point, it is assumed that nematode cuticle and mammal membranes behave in a different manner respecting drug penetration. No conclusion can be drawn by the results of the present experiments regarding the actual nature of this difference. 4-n-decyl-6-chlororesorcinol and 4-n-decylresorcinol failed to show any potentiation of in vitro activity, but, considering the result of the combination of $\mathrm{OR}$ and $\mathrm{CHCR}$, further clinical studies would be desirable.

In any case, observation of the pattern of these combined effects has proved that the anthelmintic effects of alkylhydroxybenzenes are not necessarily related to their local irritant properties and suggests a method for the improvement of certain anthelmintics.

\section{SUMMARY}

By the combination of two each of comparatively. less irritant synthetic anthelmintics, 4-n-octyl-6-chlororesorcinol, 4-n-octylresorcinol, and 4-cyclohexyl-6-chloro- 
resorcinol, fairly macked potentiation of in vitro and/or clinical anthelmintic efficacy was observed, without increase in toxicity or local irritant properties. These results indicate that certain mixtures of these compounds, such as the $70: 30$ mixture of 4-n-octyl-6-chlororesorcinol and 4-n-octylresorcinol, are superior to hexylresorcinol for the treatment of ascaris infection in man because of greater anthelmintic efficacy and lower toxicity. Synergistic mechanism of the ascaricidal effect could not be explained simply by the change of the melting points or interfacial activity.

Acknowledgments. The authors wish to express their gratitude to Prof. McKeen Cattell, Department of Pharmacology, Cornell University Medical College, for kind advices made on the English wording of this manuscript.

\section{REFEREÑCES}

1) LAMSON, P. D. AND BROWN, H. W.: J. Pharmacol. \& Exper. Therap. $5 \tilde{3}, 227$ (1935)

2) LAMSON, P. D., BROWN, H. W., STOUghtoN, R. W., HaRWOOD, P. D., BalTZLY, R. AND BASS, A.: Ibid. 53, 218 (1935)

3) LAMSON, P. D., BRown, H. W., STOUghton, R. W., HARWoOD, P. D., BAlTzly, R. AND BASS, A.: Ibid. 53, 234 (1935)

4) Lamson, P. D., Brown, H. W., Stoughton, R. W., Harwood, P. D., Baltzly, R. AND BAss, A. R.: Ibid. 53, 239 (1935)

5) LAMSON, P. D., Brown, H. W. AND WARD, C. B.: Ibid. 53, 198 (1935)

6) Lamson, P. D., Stoughton, R. W. AND Bass, A. D.: Ibid. 56, 50 (1936)

7) LAMSON, P. D., Stoughton, R. W. AND BAss, A. D.: Ibid. 56, 60 (1936)

8) Lamson, P. D., Stoughton, R. W. AND BASS, A. D.: Ibid. 56, 63 (1936)

9) HARwood, P. D.: Proc. Soc. Exper. Biol. \& Med. 32, 131 (1934)

10) YAMASAKI, H. AND ASHIKAGA, M.: Folia pharmacol. japon. 44, no. 1, Proceedings 29 \$(1948)

11) Ashikaga, M.: Ibid. 44, no. 3, Proceedings $32 \$$ (1949)

12) Yamasaki, H., ManNami, C. AND MAYeda, H.: This Journal 1, 63 (1951)

13) Stoli, N. R.: Am. J. Hyg. 3, 59 (1923)

14) DU NoüY, P. L.: J. Gen. Physiol. 1, 521 (1919)

15) Hillyer, H. W.: J. Am. Chem. Soc. 25, 1256 (1903)

16) VAN DER WAERden, B. L.: Arch. exper. Path. u. Pharmakol. 195, 389 (1940)

17) BÜrGi, E.: Med. Klin. 22, 833 (1926)

18) AleXander, A. E. ANd TRim, A. R.: Proc. Roy. Soc., London, s. B. 133, 220 (1946)

19) MANNAMI, C.: Folia pharmacol. japon. 48, 159 (1952) 